\title{
Does a Problem-Based Learning MBBS Curriculum Prepare Resident Medical Officers for Paediatric Practice in Papua New Guinea?
}

\author{
Pulsan, F. \& Vince, J.
}

\begin{abstract}
Background: How well the Problem Based curriculum at the School of Medicine and Health Sciences (SMHS) at the University of Papua New Guinea (UPNG) prepares graduates for the workforce has not been evaluated.

Methods: We used a pre tested questionnaire to explore the views of Resident Medical Officers (RMOs) on how well the curriculum had prepared them for their role as RMOs in Paediatrics. We also explored the views of clinical supervisors. Responses to a wide range of questions were scored using a 5-point Likert scale. Participants were requested to indicate skills for which they felt insufficiently prepared.
\end{abstract}

Results: Twenty-five of $38(66 \%)$ RMOs and 19 of $25(76 \%)$ clinical supervisors completed the survey. Mean scores of $\geq 3.5$ and $\geq 3.9$ were recorded for $24(69 \%)$ and $16(46 \%)$ of the 35 questions put to the RMOs. A mean score of $\leq 3$ was recorded in only $5 / 35$ questions. Only two of ten question scores for clinical supervisors' assessment of the RMOs were $<3.5$.

Discussion: The RMOs felt generally well prepared and clinicians rated RMO performance as at least satisfactory in most areas. Low scores were obtained on questions related to dealing with job stress including dealing with parents and families of children who die, and balancing personal and professional life. Participants felt that more attention should be given to neonatal and infant resuscitation during the undergraduate programme.

Conclusion: The results provide assurance that the PBL based curriculum prepares the students well for their future roles and indicate areas in which the curriculum can be modified to address perceived deficiencies.

Key words: Current Problem Based Learning Curriculum, Preparedness, Resident Medical Officers, Paediatrics, Assessment of preparation for workforce

\section{Introduction}

A curriculum based on the principles of Problem Based Learning (PBL) was implemented in the Bachelor of Medicine and Bachelor of Surgery (MBBS) programme at University of Papua New Guinea (UPNG) in 2000.

School of Medicine and Health Sciences, University of Papua New Guinea. PO Box 5623, Boroko NCD 111, Papua New Guinea.

Corresponding Author: Professor John Vince

School of Medicine and Health Sciences, University of Papua New Guinea. PO Box 5623, Boroko NCD 111, Papua New Guinea.

Email: johndvince@gmail.com
The majority of students enter the programme from the UPNG Science Foundation Year although places are reserved for first degree holders. The four year long programme is followed by 2 years of Resident Medical Officers (RMO) training, and integrates teaching in Basic Medical Sciences, Public Health, Pathology and Clinical Sciences. Tutorials are the foundation of the programme. The problems are based on health issues and diseases common to Papua New Guinea (PNG). Seminars and laboratory sessions are incorporated around the problems. History taking and clinical examination are taught during the first two years. Clinical rotations

DOI: http://doi.org/10.4038/seajme.v14i1.66

(CC) SEAJME. This is an Open Access article distributed under the terms of the Creative Commons Attribution
License (http://creativecommons.org/licenses/by/4.0/), which permits unrestricted use, distribution, and


through clinical disciplines and Urban and Rural placements occur in the final 2 years of the programme. Students take histories, perform examinations and carry out basic procedures (such as venepuncture, intravenous cannulation, lumbar puncture, urinary catheterisation, and resuscitation) under supervision. These procedures are recorded in a certification log book. It has been assumed that this experience together with the knowledge, attitudes and communication skills acquired through our programme adequately equip students for their future role as RMOs. This study aimed to test this assumption by determining the views of RMOs and clinical supervisors in Paediatrics.

\section{Methods}

This questionnaire based survey of RMOs currently working - or who had previously worked - in the Paediatric unit of Port Moresby General Hospital (PMGH), the main teaching hospital for the School of Medicine and Health Sciences (SMHS), was carried out between August and October, 2018. The questionnaire was based on the areas of practice outlined in the Preparation for Hospital Practice Questionnaire, (PHPQ) (Hill et al., 1998). Participation was voluntary. Participants were asked to score their response to 35 questions on a Likert scale from 1-5, where 1 indicated strong disagreement and 5 strong agreement. The views of clinical supervisors - registrars and senior clinicians working with the RMOs were explored using a questionnaire focused on 10 attributes relevant to work performance. RMOs were asked to indicate areas in which they felt insufficiently prepared.

Mean and standard deviation of the scores for each question were determined. A mean of $\geq 3.5$ was taken as suggestive and a score of $\geq 3.9$ very suggestive of an overall approval and a mean score of $\leq 3$ was taken to indicate an overall negative response for each attribute.

\section{Results}

Twenty-five (66\%) of the 38 RMOs and 19 (76\%) of the 25 clinical supervisors who initially agreed to take part returned completed questionnaires. Fourteen (56\%) of the RMOs were female, 15 were in the first year and 10 in the second year of RMO training and 22/25 $(88 \%)$ were aged between $23-28$ years. Of the clinicians who completed the survey, 9 were Paediatric registrars, 3 were Emergency
Medicine registrars and 7 were Paediatric Specialists.

The mean and standard deviation of the scores for each skill are shown in Table 1. A mean of $\geq 3.9$ was obtained in $16(46 \%)$ of the 35 questions and a score of $\geq 3.5$ in 24 (69\%). The highest scores were in taking a history, performing an examination, basic procedures and understanding social, cultural and family factors relating to illness. Scores of $\leq 3$ were obtained in $5(14 \%)$ questions, four of which related to dealing with job stress including dealing with parents and families of children who die, and balancing personal and professional life. A number of RMOs expressed the view that more training in neonatal and paediatric resuscitation was required in the undergraduate programme.

Scores of $\geq 3.5$ were obtained for 7 of the 10 questions to supervisors. The lowest score of 3.29 related to basic science knowledge. There was a positive perception among the supervisors that the PBL programme satisfactorily prepared the MBBS graduates for $\mathrm{RMO}$ practice in Paediatrics. (Mean 3.65; SD 0.13).

\section{Discussion}

There are few studies of preparedness for clinical practice from lower/middle income countries. There is no compelling evidence that PBL itself prepares the student for the role of RMO better than traditional curricula, but studies indicate that it may well have advantages (Dean et al., 2003; Laven et al., 2014).

The majority of RMOs felt that the current PBL programme had prepared them satisfactorily for their current role and responsibilities. Scores from clinical supervisors supported this perception. The lowest scores were on issues relating to handling emotional stress -, dealing with parents and families of children who die and with their own emotions in distressing situations. Similar findings have been reported from other studies and whilst death of any patient can be very stressful for the attending doctor, the death of children is perhaps more keenly felt and demands considerate and empathetic communication with grieving parents (Redinhaugh et al., 2003). 'Breaking Bad News' is covered in our curriculum but whether or not this can adequately prepare students for the real situation is doubtful. 
Table 1: Scores (mean and Standard Deviation (SD)) for each question

\begin{tabular}{|c|c|c|}
\hline Skills & Mean & SD \\
\hline Evaluating the impact of family factors on illness & 4 & 0.82 \\
\hline Dealing with job stress & 2.72 & 1.31 \\
\hline Performing basic procedures & 4.24 & 0.72 \\
\hline Discussing health risk factors with parents/patients & 3.96 & 1.06 \\
\hline Dealing with my emotions with distressing situations & 2.92 & 1.41 \\
\hline Dealing with most paediatric medical emergencies & 3.56 & 0.96 \\
\hline Discussing important health care strategies with parents & 3.44 & 1.19 \\
\hline Being responsible for my own learning & 4.2 & 1 \\
\hline Utilizing research skills & 3.44 & 1.19 \\
\hline Continuously evaluating my own performance & 3.72 & 0.98 \\
\hline Understanding illness relating to social conditions & 4.12 & 1.01 \\
\hline Taking the patients ethnic and cultural history into account & 4.12 & 0.93 \\
\hline Balancing job and personal life & 2.92 & 1.38 \\
\hline Encouraging patients and parent to improve life habits & 4 & 0.96 \\
\hline Using basic scientific knowledge to evaluate medical conditions & 3.96 & 0.98 \\
\hline Evaluating my own educational experiences & 3.6 & 0.87 \\
\hline Carrying out physical examination efficiently & 4.16 & 0.90 \\
\hline Taking proper history from parents/patients & 4.6 & 0.58 \\
\hline Establishing a good patient-health worker relationship & 4.04 & 0.89 \\
\hline Staying calm in difficult situations & 3.64 & 1.15 \\
\hline Investing time in developing my skills & 3.64 & 1.04 \\
\hline $\begin{array}{l}\text { Understanding the importance of group dynamics while working } \\
\text { together as a team }\end{array}$ & 4.04 & 0.89 \\
\hline Justifying the use of medicine based on mode of actions & 3.72 & 1.14 \\
\hline Selecting medications taking costs, risks, and benefits into account & 3.2 & 1.08 \\
\hline Drug calculations in Paediatrics & 3.52 & 1.26 \\
\hline Fluid calculations in Paediatrics & 3.2 & 1.29 \\
\hline Keeping computerised clinical data records & 2.76 & 1.16 \\
\hline
\end{tabular}


The transition from Medical Student to Resident Medical Officer is a time of considerable stress. The new doctor is required to take responsibility in the clinical arena and has to balance personal and professional life. Data from the UK indicate that $28 \%$ of junior doctors experience psychological stress (Iversen et al., 2009). Our study indicates that the MBBS programme ensures that the RMOs are comfortable with their clinical skills, although they felt that more attention should be given to neonatal and paediatric resuscitation in the undergraduate programme. However they felt ill prepared to cope with job stress and to balance their job and personal life. This indicates the need not only for preparing the students but also for suitably empathetic supervisors or mentors in the workplace.

This small study was limited to first and second year RMOs in Paediatrics - the authors' clinical area. The low response rate $(66 \%)$ raises the possibility of positive bias, and second year RMOs may not accurately reflect the opinions of first year RMOs. Future studies should include a larger number of RMOs in the first year of their rotations through different disciplines, and include those working in hospitals other than the main teaching hospital.

\section{Conclusion}

Whilst the current PBL programme at SMHS prepares undergraduates satisfactorily for their clinical role as RMOs in Paediatrics RMOs feel inadequately prepared to deal with work related stress.

\section{Acknowledgements}

The authors acknowledge the willing participation of the RMOs and Clinical Supervisors.

\section{Ethics Committee Approval}

Ethical Approval for the study was given by the School of Medicine and Health Sciences Research and Ethics Committee. All participants freely consented to the study.

Competing Interests: The authors declare that they have no competing interest.

\section{References}

Dean, S,J., Barratt, A.L., Hendry, G,D. \& Lyon, P.M.A. (2003) Preparedness for Hospital Practice among Graduates of a Problem-Based, Graduate-Entry Medical Program. MJA, 178, pp. 163-16.

Hill, J., Rolfe, I.E., Pearson, S.A. \& Heathcote, A. (1998) Do Junior Doctors Feel They are Prepared for Hospital Practice? A Study of Graduates from Traditional and Non-Traditional Medical Schools. Medical Education, 32, pp. 19-24.

Iversen, A., Rushforth. B. \& Forrest, K. (2009) How to Handle Stress and Look after Your Mental Health. BMJ, 338, b1368.

Laven, G., Keefe, D., Duggan, P. and Tonkin, A. (2014) How was the Intern Year? Self and Clinical Assessment of Four Cohorts, from Two Medical Curricula. BMC Medical Education, 14, 1, pp.123.

Redinbaugh, E.M., Sullivan, A.M., Block, S.D., Gadmer, N.M., Lakoma, M., Mitchell, A.M., Seltzer, D., Watford, J. \& Arnold RM. (2003) Doctors' Emotional Reactions to Recent Death of a Patient: Cross Sectional Study of Hospital Doctors. BMJ, 327, pp.185-190. 